\title{
Meconium Stained Liquor and Its Fetal Outcome - Retrospective Study
}

\author{
Dr.Meena Priyadharshini.V ${ }^{1}$, Dr. Seetha Panicker ${ }^{2}$. \\ ${ }^{1}$ (Assistant Professor, Dept Of O\&G, PSGIMS\&, Dr. MGR University,India) \\ ${ }^{2}$ (Professor \& HOD,Dept Of O\&G, PSGIMS\&R,Dr.MGR University,India)
}

\begin{abstract}
AIMS \& OBJECTIVES: To determine the fetal outcome and mode of delivery in patients with meconium stained liquor during labour.MATERIALS \& METHODS: This retrospective study was conducted from January 2012 to December 2012 on patients admitted to Labour ward,PSGIMSR. Out of 2124 deliveries,250 patients who met the inclusion criteria were enrolled in our study.The data was collected in a predesigned proforma.RESULTS: The results of fetal outcome and mode of delivery were analysed statistically using SPSS version 19. The Chi Square test was applied between Grades of Meconium and APGAR Score.p value $<0.05$ which was statistically significant. Also, the study between Grades of Meconium and CTG pattern proved to be significant with $p$ value <0.05.CONCLUSION: Meconium Stained Liquor alone is not assosiated with an adverse neonatal outcome,86\% of babies remained asymptomatic .Increasing Grade of MSL is associated with increased adverse outcome. Association of MSL with abnormal CTG is assosiated with poor outcome, Increased caesarean section rate, increased neonatal complications.
\end{abstract}

Keywords: APGAR Score, CTG, Meconium Stained Liquor, Meconium Aspiration Syndrome

\section{Introduction}

Meconium staining of the amniotic fluid has long been regarded as a sign of fetal distress. Although the exact cause is not known, meconium is thought to be passed from the fetal gastro-intestinal tract as a response to hypoxia, mesentric vasoconstriction induced gut hyperperistalsis, falling umbilical venous saturation, vagal stimulation and normal physiological function of a mature fetus.[1,2]

Conflicting outcomes have been reported in the labours, complicated by meconium staining of the amniotic fluid, varying with the degree of meconium staining.[3,4,5]

Foetal distress is defined as alterations in the foetal heart rate (FHR)more commonly bradycardia and thepassage of meconium in response to the underlying foetal hypoxia. Variations in FHR, passage of the meconium in the amniotic fluid, pathological or abnormal CTG and decreased foetal scalp blood pH are strong indicators of fetal distress.[6]

MSAF is associated with higher rate of caesarean delivery, increased need for neonatal resuscitation and meconium aspiration syndrome.[7]

The risk factors for meconium stained amniotic fluid are both maternal and fetal. The maternal factors are hpertension, Gestational Diabetes mellitus, maternal chronic respiratory or cardiovascular diseases, post term pregnancy, preeclampsia, eclampsia. The fetal factors include oligohydramnios, intrauterine growth restriction, poor biophysical profile.[8]

Aspiration of meconium by the fetus remains relatively common cause of perinatal morbidity and mortality because it is difficult to prevent.[9]

The fetus passes meconium into the amniotic fluid in 10\% of all pregnancies, in 5\% of these (1:200 of all pregnancies) the meconium is aspirated into the lungs of the fetus or the neonate[9].This can result in severe respiratory distress, meconium aspiration syndrome[9]. Thick meconium by itself is not associated with adverse foetal outcome. However, the incidence of meconium aspiration syndrome increases in case of non-reassuring FHR and clinical condition of the newborn at birth.[10,11]

The meconium aspiration syndrome can cause or contribute to neonatal death and in addition upto one-third of all cases in which aspiration occurs, develop long term respiratory compromise.[12]

The meconium stained amniotic fluid is a clinical diagnosis with no practical confirmatory test.[13]

However, various methods have been tried to detect the presence of meconium in liquor and to prevent meconium aspiration syndrome. These methods include Amnioscopy during early labour and oropharyngeal suction and endotracheal intubation after birth. The perinatal morbidity and mortality associated with meconium aspiration syndrome can be brought down if the high risks are identified in the antenatal period and careful decisions are made about the timing and mode of delivery and vigilant monitoring of the labour. This study was carried out to determine foetal outcome and mode of delivery in pregnant women with meconium stained liquor. 


\section{Aims And Objectives}

To determine the fetal outcome and mode of delivery in patients with meconium stained liquor during labour.

\section{Inclusion And Exclusion Criteria}

The inclusion criteria are gestational age $>37$ weeks, cephalic presentation, singleton pregnancy in patients with meconium stained liquor (grade I, II, III) after spontaneous or artificial rupture of membranes during labour. The exclusion criteria are gestational age $<37$ weeks, previous cesarean section, multiple pregnancy, non cephalic presentations, like breech transverse lie and compound presentation.

\section{Materials \& Methods}

After obtaining ethical clearance this retrospective study was conducted from January 2012 to December 2012.The study was done on patients admitted to labour ward, in the department of Obstetrics and Gynecology at PSG IMS\&R. Pregnant women with singleton pregnancy, cephalic presentation with more than 37 weeks of gestational age were studied. Out of 2124 deliveries, 250 patients had meconium stained liquor. All the patients in the study undergone a standardised form of labour management. The patients who fulfilled the inclusion criteria were enrolled in the study. Patients detailed history, gestational age, per abdominal examination, per speculum and per vaginal examination, admission tests including intrapartum CTG were recorded in a pre designed proforma. The patients were carefully monitored for the progress of the labour by plotting the parameters on a partogram. The fetal heart rate was strictly monitored by continuous electronic fetal monitoring. The fetal heart rate tracing were classified as normal, suspicious, abnormal according the NICE (National Institute of Clinical Exellence) guidelines.[14].The meconium staining of the amniotic fluid was classified as Grade I, II, III. By visual examination after spontaneous or artificial rupture of membranes. Grade I meconium stained liquor is translucent, light yellow green in colour, grade II MSL is opalescent with deep green and light yellow in colour. Grade III is opaque and deep green in color. Delivery is expedited when fetal heart rate abnormalities were detected by safest mode of delivery either by instrumental vaginal delivery or caesarean section. All patients underwent full trial of labour and caesarian section was done only if trial of labour was unsuccessful or if there were obstetric indications including fetal distress. The APGAR score of neonates at 5 minutes, birth weight, NICU admission, the neonates who had meconium aspiration syndrome and birth asphyxia were recorded.

\section{Results \& Observations}

Table 1: Distribution Of Meconium Stained Liquor Deliveries

\begin{tabular}{|l|l|l|l|}
\hline $\begin{array}{l}\text { Total number of } \\
\text { deliveries }\end{array}$ & $\begin{array}{l}\text { Meconium Stained Liquor deliveries } \\
\mathrm{n}=250(11.77 \%)\end{array}$ & Grade 2 MSL & Grade 3 MSL \\
\hline \multirow{2}{*}{2124} & Grade 1 MSL & $102(40.8 \%)$ & $62(24.8 \%)$ \\
\cline { 2 - 4 } & $86(34.5 \%)$ &
\end{tabular}

Table 2 - Potential Risk Factors For Meconium Stained Liquor:

\begin{tabular}{|l|l|}
\hline Antepartum Risk Factors & Intrapartum Risk Factors \\
\hline Post dated pregnancy $=82$ & Prolonged PROM $=9$ \\
\hline Pregnancy Induced Hypertension $=12$ & IUGR $=8$ \\
\hline Rh Isoimmunisation $=12$ & Prolonged Labour $=3$ \\
\hline Oligohydramnios $=9$ & Circumvallate placenta $=1$ \\
\hline Gestational Diabetes Mellitus $=8$ & Ileal Atresia $=1$ \\
\hline Heart Disease $=5$ & Premature Atrial contraction of fetus $=1$ \\
\hline Higher Maternal Age $>35$ yrs $=5$ & \\
\hline Chronic Respiratory Disease $=4$ & \\
\hline Cholestasis in Pregnancy $=3$ & \\
\hline Teen age pregnancy $=3$ & \\
\hline
\end{tabular}

Table 3 : Foetal Outcome According To Grades Of Meconium Stained Liquor \& Apgar Score

\begin{tabular}{|l|l|l|l|}
\hline Grades of MSL & $<7$ & $\geq 7$ & Total \\
\hline 1 & $12(13.95 \%)$ & $74(86.04 \%)$ & 86 \\
\hline 2 & $15(14.70 \%)$ & $87(85.29 \%)$ & 102 \\
\hline 3 & $20(32.25 \%)$ & $42(67.74 \%)$ & 62 \\
\hline Total & $47(18.8 \%)$ & $203(82.2 \%)$ & 250 \\
\hline
\end{tabular}

The Statistical Package for Social Science (SPSS 19) was used to analyse the above data and Chi Square Test 
was applied between the Grades of meconium and APGAR Score at $95 \%$ confidence interval with $p$ value $<0.05$ which is considered to be statistically significant.

Table 4 - Foetal Heart Rate Patterns On CTG With Grades Of Meconium Stained Liquor

\begin{tabular}{|l|l|l|l|l|}
\hline Grade of MSL & Normal $(\mathrm{n}=110)$ & Suspicious(n-=90) & Abnormal(n=50) & Total(n=250) \\
\hline 1 & $49(56.97 \%)$ & $28(32.55 \%)$ & $9(10.46 \%)$ & 86 \\
\hline 2 & $45(44.11 \%)$ & $38(37.25 \%)$ & $19(18.62 \%)$ & 102 \\
\hline 3 & $16(25.80 \%)$ & $24(28.70 \%)$ & $22(35.48 \%)$ & 62 \\
\hline
\end{tabular}

The SPSS 19 was used to analyse the above data and Chi Square was applied between the Grades of Meconium and fetal heart rate patterns on CTG at $95 \%$ confidence interval with $\mathrm{p}$ value $<0.05$ which is considered to be statistically significant.

Table 5- Birth Weight \& Grade Of Meconium Stained Liquor

\begin{tabular}{|l|l|l|}
\hline Grade of MSL & $<2.5 \mathrm{Kgs}$ & $\geq 2.5 \mathrm{Kgs}$ \\
\hline 1 & $10(34.48 \%)$ & $76(34.38 \%)$ \\
\hline 2 & $13(44.82 \%)$ & $89(40.27 \%)$ \\
\hline 3 & $6(20.68 \%)$ & $56(22.62 \%)$ \\
\hline Total & $29(11.6 \%)$ & $221(88.4 \%)$ \\
\hline
\end{tabular}

Table 6- Neonatal Outcome According To Grades Of Meconium Stained Liquor

\begin{tabular}{|l|l|l|l|l|l|}
\hline \begin{tabular}{l} 
Grade $\begin{array}{l}\text { Meconium } \\
\text { stained liquor }\end{array}$ \\
\cline { 2 - 6 }
\end{tabular} & $\begin{array}{l}\mathrm{n}=250 \\
\begin{array}{l}\text { Asymptomatic } \\
\text { Routine care at } \\
\text { birth }\end{array}\end{array}$ & NICU Admission & Ventilator & MAS & $\begin{array}{l}\text { Birth } \\
\text { asphyxia }\end{array}$ \\
\hline 1 & 79 & $7(8.1 \%)$ & 1 & 1 & 1 \\
\hline 2 & 95 & $7(6.86 \%)$ & 4 & 3 & 1 \\
\hline 3 & 41 & $21(33.87 \%)$ & 12 & 10 & 3 \\
\hline Total & $215(86 \%)$ & $35(14 \%)$ & $17(48.57 \%)$ & $14(40 \%)$ & $5(14.28 \%)$ \\
\hline
\end{tabular}

Table 7 - Mode of Delivery \& Grades Of Meconium Stained Liquor

\begin{tabular}{|l|l|l|l|l|}
\hline Grades of MSL & Normal delivery & Instrumental delivery & LSCS & Total \\
\hline 1 & $46(53.48 \%)$ & $17(19.76 \%)$ & $23(26.74 \%)$ & 86 \\
\hline 2 & $36(35.29 \%)$ & $26(25.49 \%)$ & $40(31.21 \%)$ & 102 \\
\hline 3 & $4(6.45 \%)$ & $15(24.19 \%)$ & $43(69.35 \%)$ & 62 \\
\hline Total & $86(34.4 \%)$ & $58(23.2 \%)$ & $106(42.4 \%)$ & 250 \\
\hline
\end{tabular}

\section{Discussion}

Fetal condition during labour is usually assessed by fetal heart rate and checking the presence of meconium in the amniotic fluid.[14,15].

The passage of meconium may be a normal physiological event reflecting fetal maturity. It may on the other hand reflect fetal hypoxia or increased vagal activity from cord compression.[16].

The detection of MSL during labour often causes apprehension and anxiety for the patient as well as the health provider as it is often considered as indication of fetal distress[17].

Generally thick meconium is associated with poor perinatal outcomes. $[18,19]$

The exact reason of passage of meconium in the liquor is poorly understood. It could reflect the state of compensated fetal distress as it is suggested by few babies who are actually acidotic during labour[20].

Acute or chronic fetal hypoxia can result in the passage of meconium in utero[21].

Also the incidence of meconium passage during labour increases with gestational age 30\% at 40 weeks, $50 \%$ at 42 weeks.[22].

The MSAF and its association are still very important determinants of perinatal morbidity and mortality and a successful management of such pregnancies is only possible after better understanding pathophysiology of meconium passage[23].

Presence of meconium below vocal cord is known as meconium aspiration and occurs in $20-30 \%$ of all infants with MSAF with around $12 \%$ mortality[24].

MSAF alone is not an indication for caesarian section, however with MSAF needs strict supervision during labour for better perinatal outcome[25]. The low apgar scores may be because of direct vasoconstrictor effect of meconium on umblical vein that results in vasospasm in leading to impaired placental blood flow[26]. Infants with APGAR Score $<7$ at $5 \mathrm{~min}$ are three times more likely to have abnormalities on neurological examination[27]. 
Presence of meconium in absence of fetal heart rate abnormalities is not suggestive of fetal compromise and does not require any intervention[28]. The increased rate of emergency Caesarean Section, Instrumental Vaginal Delivery for fetal distress, meconium aspiration syndrome and neuro developmental handicaps are possible problems with MSAF [29].

After the initial hypoxic bout initiating the passage of meconium, subsequent repetitive bouts due to prolonged labour or abnormal uterine activity may cause severe asphyxia [30]. Such repetitive bouts can be avoided by careful fetal monitoring, active management of labour and optimal care after birth. This would help avoid unnecessary caesarian sections in all cases of meconium stained liquor in absence of a defenitive indication. The clinical diagnosis of perinatal asphyxia is based on several criteria, the two main ones being evidence of cardiorespiratory and neurological depression (Defined as an APGAR Score remaining $<7$ at 5 min after birth) and evidence of acute hypoxic compromnise with acidemia.[31].

In our study, the total number of deliveries was 2124 , among which there were $250(11.77 \%)$ patients with meconium stained amniotic fluid. Grade I MSL $=86(34.4 \%)$, Grade $2 \mathrm{MSL}=102(40.8 \%)$, Grade $3 \mathrm{MSL}$ $=62(24.8 \%)$. (Table 1). Nirmala et al, in her study, showed that there were 1267 deliveries among which MSL $=$ 100(7.89\%); Grade $1 \mathrm{MSL}=39 \%$, grade $2 \mathrm{MSL}=43 \%$, grade $3 \mathrm{MSL}=18 \%$.[32]. Surekha et al, in her study, there were 3673 deliveries among which MSL deliveries $=120(3.48 \%)$; Grade $1 \mathrm{MSL}=34.16 \%$, Grade $2 \mathrm{MSL}=$ $29.16 \%$, Grade $3 \mathrm{MSL}=36.66 \%$.[33]. Rev Sauda et al, in his study, he observed 11.9\% of MSL deliveries.[34]. In our study, out of 250 MSL deliveries, the potential antepartum risk factors for meconium stained liquor were post dated pregnancy(82), PIH(12), Rh isoimmunisation(12), Oligohydramnios(9), $\operatorname{GDM}(8)$, Heart disease(5), Higher Maternal Age(5), Chronic Respiratory disease(4), Teen age pregnancy(3), Cholestasis of pregnancy(3).The intrapartum risk factors were prolonged PROM (9), IUGR(8), Prolonged labour(3), Circumvallate Placenta(1), Ileal Atresia(1), Premature atrial contraction of fetus(1).(Table 2). Shankyan et al, in his study, the risk factors for MSL out of 159 deliveries were Postdated pregnancy(47), IUGR(21), PROM(20), Higher Maternal Age (19), PIH(17).

In our study, there were 47(18.8\%)babies with APGAR Score $<7$ among which,12(13.9\%) babies were in Grade I MSL, 15(14.70\%)babies were in Grade 2 MSL and 20(32.25\%)in Grade 3 MSL; p value $=<0.05$, Statistically Significant.(Table 3). In contrast to our study, Nirmala et al in her study, there were only one baby $(0.18 \%)$ in Grade 3 MSL, no babies in Grade 1 and Grade 2 MSL at 5 minute APGAR Score <7.[32].

In our study, the normal CTG patterns were $49(56.97 \%)$ in Grade I MSL, 45(44.11\%) in Grade 2 MSL and 16(25.80\%) in Grade 3 MSL; Suspicious CTG patterns were 28(32.55\%) in Grade I MSL, 38(37.25\%) in Grade 2MSL, 24(28.70\%) in Grade 3 MSL; Abnormal CTG patterns were 9(10.46\%)in Grade 1 MSL, $19(18.62 \%)$ in Grade 2 MSL, 22(35.48\%) in Grade 3 MSL.( Table 4). Among the 22 babies with abnormal CTG patterns, in Grade 3 MSL, 15 babies needed NICU admission; among those 15 babies, 12 of them needed ventilatory support of which 10 babies developed meconium aspiration syndrome and 3 babies had severe Birth Asphyxia. Nirmala et al, in her study, the normal CTG patterns were 25(64.1\%) in Grade I MSL, 28(65.11\%) in Grade 2 MSL, 10(55.5\%) in Grade 3 MSL; Suspicious CTG patterns were 10(25.64\%) in Grade I MSL, $10(23.25 \%)$ in Grade 2 MSL, 5(27.77\%) in Grade 3 MSL; Abnormal CTG patterns were 4(10.25\%) in Grade I MSL, 5(11.62\%) in Grade 2 MSL, 3(16.66\%) in Grade 3 MSL.[32].

In our study there were $29(11.6 \%)$ babies with birth weight $<2.5 \mathrm{~kg}$ among which Grade 1 MSL10(34.48\%). Grade 2 MSL-13(44.82\%). Grade 3 MSL-6(20.68\%).(Table 5).In contrast to our study, Nirmala et al in her study, observed birth weight $<2.5 \mathrm{~kg}$ in $1(2.6 \%)$ with Grade $1 \mathrm{MSL}, 2(4.65 \%)$ in Grade $2 \mathrm{MSL}$, $2(11.11 \%)$ in Grade 3 MSL.[32]. On the other hand, Rekha Kumari et al in her study, observed birth weight $<2.5 \mathrm{~kg}$ in $30(40 \%)$ of the neonates who had MSL.[36].

In our study, 215(86\%) of babies remained asymptomatic and required only routine care at birth. $35(14 \%)$ of babies required NICU admission. Of these 35 babies, 17(48.57\%) of babies needed ventilatory support and among them, 14(40\%) developed meconium aspiration syndrome and 5(14.28\%) had severe birth asphyxia. (Table 6). Rekha Kumari et al in her study, 63(84.0\%) were asymptomatic and 1(1.3\%) had birth Asphyxia.[36]. Khazardoost et al observed 64(21.1\%) with meconium aspiration syndrome.[37]. Espinheira MC et al in his study, there were $1.4 \%$ of NICU admission of which $43.1 \%$ needed ventilatory support and $5 \%$ had meconium aspiration syndrome.[38].

In our study, there were 86(34.4\%)vaginal deliveries, 58(23.2\%) instrumental vaginal delivery and $106(42.4 \%)$ caesarean section.(Table 7).The total number of vaginal deliveries including instrumental vaginal deliveries were 144(56.7\%). The caesarean sectionrate is higher among Grade 2 and 3 MSL compared to Grade $1 \mathrm{MSL}$ in our study. Patil et al in his study, showed the caesarean rate as 42\%.[39]. Espinheira MC et al in his study, showed the caesarean rate as $62.5 \%$.[38].

\section{Conclusion}

Meconium Stained Liquor alone is not associated with an adverse neonatal outcome, $86 \%$ of babies remained asymptomatic inspite of MSL and required only routine care. Increasing Grade of MSL is associated 
with increased adverse outcome. Association of MSL with abnormal CTG is associated with poor outcome, increased caesarean section rate, increased neonatal complications.

Ethical Clearance- Obtained from IHEC PSGIMS\&R.

Conflict of Interest- None

Source of funding- Hospital

[1]. Walker J.Fetal distress.Am J Obstet Gynecol 1959;77:94-98].

[2]. Fenton AN,Steer CM Fetal distress.Am J Obstet Gynecol 1962;83:354-59].

[3]. Low JA ,Pancham SR ,Worthington O ,Bolton RW.The incidense of fetal asphyxia in 600 high risk monitored pregnancies. Am $J$ Obstet Gynecol 1975;121:456-59.55]

[4]. Meis PJ,Hall M ,Marshall JR ,Hobel CJ.Meconium passage: a new classification for risk assessment during labour. Am J Obstet Gynecol 1978;131:509-13].

[5]. Abramovici H, Brandes JM,Fuchs K ,Timor FI.Meconium during delivery, a sign of compensated fetal distress.Am $J$ Obstet Gynecol 1974;118:251-55]

[6]. Wong SF ,Chow KM, Ho LC .The relative risk of foetal distress in pregnancy associated with meconium stained liquor at different gestations. AMJ.Obstet Gynaecol 2002;22:594-9].

[7]. Shaikh EM , Mehmood S, Shaikh MA .Neonatal outcome in meconium stained amniotic fluid - one year experience.J Pak Med Assoc $2010 ; 60: 711-4$ ].

[8]. Hackey WE. Meconium Aspiration. In; Gomella TL. Neonatology.4 ${ }^{\text {th }}$ Edition.Newyork; Lange Medical Books; 1999. P.507.

[9]. Ashfaq F,Shah AA, Effect of amnioinfusion for meconium stained amniotic fluid on perinatal outcome. J Pak Med Assoc 2004 ;54:322-5].

[10]. Paz Y , Solt I Zimmer EZ. Variables assosiated with meconium aspiration syndromein labour with thick meconium. Eur J Obstet Gynaecol Reprod Biol 2001; 94;27-30

[11]. Bhutta ZA, Jalil S.Meconium aspiration syndrome: the role of resuscitation and tracheal suction in prevention . Asia Oceania $J$ Obstet Gynaecol $1992 ; 18: 13-7$ ].

[12]. Steer PJ ,Daniethian P.Foetal distress in labour. In: James DK, Steer PJ, Weiner CP, Gonaik B editors. High risk pregnancy:management options. 3rdedition. Philadelpia: Elsevier Inc 2006:pp 1450-72]

[13]. Tybulweicz AT, Clegg SK, Fonte GJ Stenson BJ .Preterm meconium staining of the amniotic fluid: associated finding and risk of adverse clinical outcome. Arch Dis Child Foetal Neonatal Ed 2004; 89:F328-30].

[14]. NICE, intrapartum guideline 55, London: national institutefor health and clinical excellence,2007.

[15]. Gee H Routin interpartum care; an overview. In : Luesley DM, Baker PN. Obstetrics and gynecology : an evidence based test for MRCOG, 2nd edition. Hodder Arnold 2010:287-95.

[16]. Ahanya SN, Lakshmanan J, Morgan DL, Ross MG. Meconium passage in utro: mechanism consequences and management. Obstet gynecological surv 2004, 60:45-56)

[17]. Naqvi SB,Manzor S. association of MSAF with perinatal outcome in pregnant women of 37-42 weeks gestation. Pak J Surg 2011; 27(4):292-298)

[18]. Rossi EM, Philipson EH Williams TG Kalhan SC, meconium aspiration syndrome: intra partum and neonatal attributes. AMJ Obstet gynecol 1989 161:1106-10

[19]. Arrow naranga et al management of mecosaf: a team approach. Indian pediatr 1993, 30:9-13.

[20]. Abramovici et al . meconium during delivery a sign of compensated fetal distress. AMJ obstet gynecol 1974:118;215-55.

[21]. Stark A et al meconium aspiration. Manual of neonatal care 2003;5:402-3.

[22]. Steer PJ et al ,fetal distress in labour, high risk pregnancy management options .3rd edition, Philedelphia ,elselver INC 2006; PP1450-72.

[23]. Sinsck et al .A long standing incomprehensible matter of obstetrics :meconium-stained amniotic fliud ,a new approach to reason .Arch gynaecol obstet 2008;278:559-63).

[24]. Khatun et al ;fetal outcome in deliveries with MSL - Bangladesh. J child health ,2009;33(2):41-50

[25]. Sasaikala et al .Perinatal outcome in relation to mode of delivery in meconium stained amniotic fluid .Indian J Pediatr ,1995; 62:6367.

[26]. Althusler $\mathrm{G}$, hyde $\mathrm{S}$ the meconium induced vasoconstriction ;potential cause of cerebral and other fetal hypoperfusion and of poor pregnancy outcomes .J child neurol, $1989 ; 4: 137-42$.

[27]. Levene MI, Sands C, Grindulis H et al; Comparison of two methods of predicting outcome in perinatal asphyxia, Lancet 1:67-69, 1986.

[28]. Miller FC meconium staining of amniotic fluid ,Clin obstet gynaecol $1975 ; 121: 45-50$

[29]. Maymon et al MSAF in very low risk pregnancies at term gestation .Eur J obstet gynaecol reprod biol 1988;80:169-73.

[30]. Fujikureat et al .The significance fo meconium staining. AMJ obstet gynaecol 1975;121:45-50).

[31]. William McGuire et al; BMJClinical Evidence 2007;11:320)

[32]. Nirmala Dhuhan et al, Meconium staining of amniotic fluid,a poor indicator foetal comprimise. J k science vol 12 no.4 oct- dec 2010

[33]. Surekha Tayade et al, The significance of meconium stained amniotic fluid - A cross sectional study in rural set up. $I J$ BAR (2012) 03 (12)

[34]. Rev suadha et al, MSAF \& maternal \& neonatal factors associated. Rev saudepublica 2012 dec; 46(6): 1023-9 \& pub 2013 Jan 28.

[35]. Shankyan et al, Predictors of Meconium Stained Amniotic Fluid: A possible strategy to reduce neonatal morbidity and mortality; obstet Gynaecol India Vol.56,No.6:November/ December 2006 pg 514-517

[36]. Rekha Kumari et al, Foetal outcome in patients with meconium stained liquor. J pak med assoc. 2012 may ; 62(5) ; 474-6

[37]. Khazardoost et al, risk factors for MA in MSAF, J Obstet gynaecol 2007 aug: 27(6); 577-9

[38]. Espinhera MC et al, Meconium aspiration syndrome - the experience of a tertiary centre.Rev portal pneumol 2011mar - apr ; 17(2):71-6.

[39]. Patil et al, A one year cross sectional study of management practices of MSAF \& perinatal outcome. J Obstet gynecol india 2006; 56(2): 128-130. 